\title{
A NOVEL FARADAY CUP FOR THE SIMULTANEOUS \\ OBSERVATION AND MEASUREMENT OF ION-BEAM CURRENTS
}

Ching-Yeu Wei and David N. Seidman

Cornell University

Ithaca, New York 14853

July 1977

Report \#2864

Issued by

The Materials Science Center

$$
\begin{aligned}
& \text { This report was prepared as an account of work } \\
& \text { sponsored by the United States Government. Neither the } \\
& \text { United States nor the United States Department of } \\
& \text { Energy, nor any of their employees, nor any of their } \\
& \text { contractors, subcontractors, or their employees, makes } \\
& \text { any warranty, express or implied, or assumes any legal } \\
& \text { liability or responsibility for the accuracy, completeness } \\
& \text { or usefulness of any information, apparatus, product or } \\
& \text { process disclosed, or represents that its use would not } \\
& \text { infringe privately owned rights. }
\end{aligned}
$$

PREPARED FOR THE U.S. ENERGY RESEARCH AND DEVELOPMENT ADMINISTRATION UNDER CONTRACT NO. EY-76-5-02-3158.*000. 


\section{DISCLAIMER}

This report was prepared as an account of work sponsored by an agency of the United States Government. Neither the United States Government nor any agency Thereof, nor any of their employees, makes any warranty, express or implied, or assumes any legal liability or responsibility for the accuracy, completeness, or usefulness of any information, apparatus, product, or process disclosed, or represents that its use would not infringe privately owned rights. Reference herein to any specific commercial product, process, or service by trade name, trademark, manufacturer, or otherwise does not necessarily constitute or imply its endorsement, recommendation, or favoring by the United States Government or any agency thereof. The views and opinions of authors expressed herein do not necessarily state or reflect those of the United States Government or any agency thereof. 


\section{DISCLAIMER}

Portions of this document may be illegible in electronic image products. Images are produced from the best available original document. 
A NOVEL FARADAY CUP FOR THE SIMULTANEOUS OBSERVATION

AND MEASUREMENT OF ION-BEAM CURRENTS *

Ching-Yeu Wei and David N. Seidman

Department of Materials Science and Engineering and the Materials Science Center, Cornell University, Bard Hall, Ithaca, New York 14853

\section{ABSTRACT}

A novel Faraday cup is described which allows the simultaneous observation and measurement of ion-beam currents. The Faraday cup is constructed around a Galileo channel electron multiplier array (CEMA) which serves as the basis of an internal image intensification system (a gain of $>10^{4}$ ) for the observation of the ion beam; the CEMA also acts as a collector for the ion current which is measured by a Keithley 602 electrometer. The ion current is integrated by a simple and inexpensive dosimeter; the electronic circuit for the dosimeter is described. The application of the Faraday cup to the observation and measurement of a $30 \mathrm{keV} \mathrm{Ar}{ }^{+}$ion beam is presented as an illustrative example. We have also employed this Faraday cup to observe and measure $30 \mathrm{keV} \mathrm{Cr}{ }^{+}$, $\mathrm{Mo}^{+}$or $\mathrm{W}^{+}$and 18 $\mathrm{keV} \mathrm{Au}{ }^{+}$ion beams employed for the in-situ irradiation of field-ion microscope specimens.

Research supported by the U.S. Energy Research and Development Administration. Additional support was received from the National Science Foundation through the use of the technicla facilities of the Materials Science Center at Cornell University. 


\section{INTRODUCTION}

For the past few years we have employed energetic ( $10-45 \mathrm{keV}$ ) positivelycharged metal ion-beams to irradiate metal field-ion microscope (FIM) specimens. (1-9) The irradiations have been performed in-situ under ultra-high vacuum [ ( 0.2 to 2$) \times 10^{-9}$ Torr] conditions in a stainless steel FIM; the FIM specimen is attached to the tail of a continuous-transfer liquid-helium cryostat via a copper FIM specimen holder that is clamped to a sapphire piece that serves to electrically isolate the specimen holder from the cryostat. (10) The main problems with the in-situ irradiations were the alignment and observation of the ion beam with respect to the FIM tip and the accurate measurement of the ion dose. Prior to the use of the design described in this paper we had employed a phosphor screen to first align and observe the ion beam and then a separate Faraday cup to measure the ion dose. This arrangement had the following deficiencies: (1) it was cumbersome; (2) it was time consuming; and (3) the

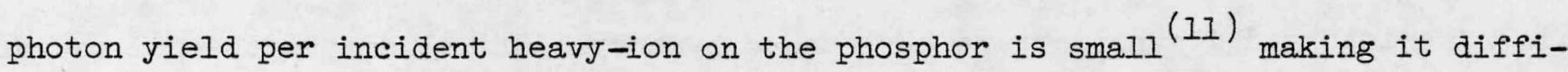
cult to visually observe a heavy-metal or gas ion-beam (e.g., $30 \mathrm{keV} \mathrm{Ar}^{+}, \mathrm{Cr}^{+}$, $\mathrm{Mo}^{+}$or $\left.\mathrm{W}^{+}\right)$.

To correct these problems we have designed and constructed a Faraday cup which allows us to both continuously and simultaneously monitor the ion-beam cross-section and ion dose. At the heart of the present system is a Galileo channel-electron multiplier array (CEMA) which serves as the basis of an internal image intensification system to observe the ion beam and also as an ion-beam collector in the Faraday cup. This design overcomes the major problem inherent to a conventional Faraday cup design; i.e., the inability to simultaneously observe the profile of the ion beam and to measure the ion dose. The present paper describes this novel Faraday cup which corrects the above mentioned problem; 
in addition, a simple dosimeter is described which gives a direct readout of the integrated flux (i.e., the dose). The use of this Faraday cup to measure and observe an ion current of $2 \times 10^{-9}$ amp of $30 \mathrm{keV} \mathrm{Ar}$ ions is presented as an illustrative example of the capabilities of the present design. In addition, we have also used the present design to observe and measure $30 \mathrm{keV} \mathrm{Cr}^{+}, \mathrm{Mo}^{+}$or $\mathrm{W}^{+}$and $18 \mathrm{keV} \mathrm{Au}{ }^{+}$ion beams during the in-situ irradiation of tungsten FIM specimens. There appears to be no fundamental limitation on the application of this design to the observation and measurement of all the elements in the periodic table that one can make into positively or negatively charged ion-beams.

II. DESIGN AND PERFORMANCE OF THE FARADAY CUP

A. The Faraday cup and the channel electron multiplier array.

Figure 1 shows a cross-sectional top view of the Faraday cup (right-hand side) and its relationship to the FIM specimen (left-hand side). The FIM specimen is in the form of an $\sim 1 \mathrm{~cm}$ long wire ( 0.13 to $0.20 \mathrm{~mm}$ in diameter) which is sharply pointed and is mounted on an hexagonal-shaped copper FIM specimen holder. The FIM specimen and its holder are surrounded by a cylindrical copper thermal radiationshield which contains two apertures; the first aperture defines the cross-sectional area of the ion beam that impinges on the FIM specimen specimen. The second aperture is made larger in diameter than the first one to avoid an ion-beam shadowing effect. In addition, a piece of gold metal is attached to the cylindrical thermal copper radiation-shield on the side of the first aperture to further shield the Faraday cup from any portion of the ion beam which may accidentally by-pass the first aperture.

The ion beam that passes through the second aperture of the cylindrical copper thermal radiation-shield next enters the Faraday cup as it passes through an annular stainless steel ring that serves the role of a secondary-electron retarder; the latter is biased at $-300 \mathrm{Vdc}$. The secondary-electron retarder prevents electrons that are produced inside the secondary-electron collection-cylinder, floating at $0 \mathrm{~V}$, from escaping from the Faraday cup and it also prevents stray electrons from entering the Faraday cup. The long stainless steel secondary-electron collection- 
cylincier serves to recapture any secondary-electrons that are released by the ion beam. Finally the ion beam ${ }^{(10)}$ is collected on the front surface of the CEMA, which is also floating at $\mathrm{O}$, and it is measured with a Keithley 602 electrometer. The incident ion-beam current is also converted to an electron current by the CEMA. (13) The back surface of the CEMA is maintained at $+900 \mathrm{Vdc}$; the voltage drop of $900 \mathrm{Vdc}$ across the CEMA produces a gain of $110^{4}$. The CEMA is separated from a P-I phosphor screen ${ }^{(14)}$, deposited on a glass plate, by a $1.6 \mathrm{~mm}$ thick annular ring fabricated from Corning No. 2598 machinable glass. The electron current produced by the CEMA is accelerated and proximity focused onto the phosphor screen which is maintained at $+1500 \mathrm{Vdc}$; the glass plate, on which the phosphor is deposited, is coated with a conducting layer of tin oxide. $(15,16)$ The visible light given off by the phosphor is observed through an $22.5 \mathrm{~cm}$ diameter glass window on the FIM. An example of the observational capability of the CEMA portion of the Faraday cup is shown in Fig. 2. Figure 2a shows the cross-sectional image of a $30 \mathrm{keV} \mathrm{Ar}{ }^{+}$ion beam at a current density of $\sim 4 \times 10^{-9}$ amp $\mathrm{cm}^{-2}$. Figure $2 \mathrm{~b}$ shows an FIM specimen which was biased at 600 Vdc to give a shadowgraph of the tip in the ion beam; this technique has been found to be extremely useful for rapidly aligning the FIM specimen with respect to the ion beam.

B. Measurement of the positive ion current

The problem of measuring the total ion current $\left(I_{i}\right)$ is best explained with the aid of the approximate equivalent circuit, shown in Fig. 3, for the irradiation system and the Faraday cup. The numbered points 0 to 3 , at the top of the circuit, correspond to the secondary-electron retarder (0), the front surface of the CEMA (1), the back surface of the CEMA (2) and the phosphor screen (3). The total ion current enters the Faraday cup at the point 0 from the irradiation system; the diode used in the irradiation system portion of the diagram indicates symbolically that a reverse positive-ion current is not possible in this portion of the circuit. The quantity $I_{i}$ can divide itself into three separate ion currents 
$I_{i 1}, I_{i 2}$ and $I_{i 3}$ at the points 1,2 and 3 respectively; in general it is expected that $\left(I_{i 2}+I_{i 3}\right)<I_{i 1}$. The ion currents $I_{i 1}, I_{i 2}$ and $I_{i 3}$ rejoin at point $F$ and flow through the Keithley 602 electrometer. The electron current in the loop $1,2,3, V_{3}, V_{2}$ and $F$, denoted $I_{e}$, is not measured by the electrometer whereas the leakage currents $I_{\ell 1}, I_{\ell_{2}}$ and $I_{\ell_{3}}$ flowing from points $V_{1}, V_{2}$ and $\mathrm{V}_{3}$, respectively, to the earth ground are measured by the electrometer. Therefore the total current $I_{0}$ measured by the electrometer (EM) is given by

$$
\begin{aligned}
I_{0} & =\sum_{j=1}^{3} I_{i j}-\sum_{k=1}^{3} I_{l k} \\
& =I_{i}-\sum_{k=1}^{3}\left(V_{k} / R_{l k}\right)
\end{aligned}
$$

where $V_{k}$ is the voltage at the points $V_{1}, V_{2}$, and $V_{3}$ respectively and $R_{l k}$ is the insulation resistance between the point $\mathrm{V}_{\mathrm{k}}$ and the earth ground. Employing Eq. (Ib) it can be shown (assuming that $3 R_{l} \simeq R_{l_{1}} \simeq R_{l_{2}} \simeq R_{l_{3}}$ ) that $R_{l}$. should be greater than $10^{14} \Omega$ if the total leakage current $\left(\sum_{k=1}^{3} I_{\ell k}\right)$ is required to be less than $10^{-11} \mathrm{amp}$; this value of $10^{-11}$ amp corresponds to $1 \%$ of a typical minimum value, for our research, of $I_{i}=10^{-9} \mathrm{amp}$. In practice the leakage current was minimized by employing Corning machinable glass No. 2598 to insulate the Faraday cup from the surrounding wall of the FIM; this machinable glass has a volume resistivity of $210^{17} \Omega-\mathrm{cm}$ at $25^{\circ} \mathrm{C}$. It was estimated that $R_{\&}$ is greater than $10^{15} \Omega$.

The three required voltages $(-300,900$ and $1500 \mathrm{Vdc})$ for the Faraday cup [see Figs. 1 and 3] are provided by six Burgess U-200 dry cell batteries which are mounted in a specially constructed plexi-glass box. Inside the FIM the leads from the Faraday cup are sparkwelded to four Ceramseal feedthroughs which are mounted on a standard 2-3/4 inch diameter doublesided Varian Conflat flange. Outside the FIM we employed MHV coaxial connecters and polyethylene cable to 
provide maximum electrical insulation. Control experiments have demonstrated that the total leakage current is always less than $3 \times 10^{-12}$ amp and that a value of $1 \times 10^{-12}$ amp is very typical; the latter value is only $0.1 \%$ of the minimum ion current of $1 \times 10^{-9}$ amp used in a typical charged particle irradiation in our research.

\section{A SIMPLE DOSTMETER}

The current $I_{0}$, which is essentially equal to the quantity $I_{i}$, is measured by a Keithley 602 electrometer. Since an important physical quantity, for every irradiation, is the total dose (i.e., the integrated flux); a simple and inexpensive dosimeter was constructed to integrate the $I_{i}$ with respect to time. (15) The Keithley 602 electrometer converts $I_{0}$ to an equivalent voltage $\left(V_{\text {in }}\right)$; this electrometer provides an output voltage of I Vdc for full-scale meter deflection on any current range.

Figure 4 shows the schematic diagram for the dosimeter ${ }^{(17)}$ which is essentially an analog integrater. An adjustable voltage source is connected to the non-inverting input of the difference amplifier to diminish the self-integration of the integrater to less than $10 \mu \mathrm{V} \mathrm{sec}-1$. The multiplier stage is used to calibrate the output voltage $\left(\mathrm{V}_{\text {out }}\right)$; the quantity $\mathrm{V}_{\text {out }}$ is given by the equation

$$
\mathrm{V}_{\text {out }}=\beta \int \mathrm{V}_{\text {in }}(t) d t
$$

where $\beta$ is an adjustable constant with the dimensions of $\sec ^{-1}$.

Let us now consider an example of how Eq. (2) was used in practice. The object was to obtain a value of $\mathrm{V}_{\text {out }}$ which was proportional to the total dose; for example, for $I_{0}=10^{-9} \mathrm{amp}$, an irradiation time of $600 \mathrm{sec}$ and an ion-beam cross-sectional area of $0.5 \mathrm{~cm}^{2}$ the dose is $0.75 \times 10^{13}$ ion $\mathrm{cm}^{-2}$; thus we calibrated the dosimeter to obtain $V_{\text {out }}=0.75 \mathrm{Vdc}$. For $I_{0}=10^{-9}$ amp the value of $V_{\text {in }}$ is $0.33 \mathrm{Vdc}$ using the $3 \times 10^{-9}$ amp range on the electrometer; therefore, employing Eq. (2) 


$$
\mathrm{V}_{\text {out }}=3.75 \times 10^{-3} \int \mathrm{v}_{\text {in }}(t) \mathrm{dt}
$$

for this scale of the electrometer and for the cross-sectional area of $0.5 \mathrm{~cm}^{2}$; we note that $I_{0}$ need not be constant for Eq. (2) to be valid. The dosimeter can, of course, be calibrated in a similar manner for any other ion-beam crosssectional area or current scale of the electrometer. The dosimeter was found to be particularly useful in terminating the ion irradiation at some pre-determined dose.

\section{ACKNOWLEDGEMENTS}

We wish to thank Dr. Guy Ayrault, Dr. Huei-Pei Kou and Mr. Alfred Wagner for useful discussions. 


\section{FIGURE CAPTIONS}

Fig. 1: A schematic diagram (top view) showing the relationship of the FIM specimen (left-hand side of the figure) to the Faraday cup (right-hand side of the figure).

Fig. 2: (a) A photograph of the image of a $30 \mathrm{keV} \mathrm{Ar}^{+}$ion beam with the FIM tip at earth potential; the current is $2 \times 10^{-9}$ amp on an area of $0.5 \mathrm{~cm}^{2}$.

(b) In this case the FIM tip is at a potential of +600 Vdc and the shadow of conically-shaped tip is readily seen; same $\mathrm{Ar}^{+}$ion current. Both images were recorded on Polaroid 3000 ASA film.

Fig. 3: An equivalent circuit for the irradiation system and the Faraday cup; the ion-beam current is $I_{i}$ and the current measured by the electrometer (EM) is $I_{0}$. In practice $I_{0}$ is almost equal to $I_{i}$ since the leakage resistance $\left(R_{\ell 1}, R_{\ell_{2}}\right.$ and $\left.R_{\ell 3}\right)$ is very large $\left(10^{15} \Omega\right)$; see Section II.B for a detailed discussion.

Fig. 4: The electronic circuit for the dosimeter used to measure the integrate flux during an irradiation. The input voltage $\mathrm{V}_{\text {in }}$ is provided by the Keithley 602 electrometer (see Fig. 1). 


\section{REFERENCES}

1. R.M. Scanlan, D.I. Styris and D.N. Seidman, Phil. Mag. 23, 1439 and 1459 (1971).

2. P. Pétroff and D.N. Seidman, Acta Met. 21, 323 (1973).

3. D.N. Seidman, J. Phys. F: Metal Phys. 3 , 393 (1973).

4. K.L. Wilson and D.N. Seidman, in Defects and Defect Clusters in B.C.C. Metals and Their Alloys, edited by R.J. Arsenault (University of Maryland, College Park, MD, 1973), pp. 216-39.

5. K.L. Wilson and D.N. Seidman, Rad. Effects 27, 67 (1975).

6. D.N. Seidman, K.L. Wilson and C.H. Nielsen, in Proc. of International Conference on Fundamental Aspects of Radiation Damage in Metals, edited by M.T. Robinson and F.W. Young, Jr. (National Technical Information Service, Springfield, VA, 1975), Vol. I, pp. 373-96.

7. D.N. Seidman, in Radiation Damage in Metals, edited by N.L. Peterson and S.D. Harkness (American Society for Metals, Metals Park, OH, 1976), pp. 28-57.

8. C.-Y. Wei and D.N. Seidman, Rad. Effects 32, 229 (1977).

9. C.-Y. Wei and D.N. Seidman, Cornell Materials Science Center Report \#2398 (1977); submitted for publication (1977).

10. D.N. Seidman, R.M. Scanlan, D.L. Styris and J.W. Bohlen, J. Sci. Instrum. 2,473 (1969).

11. D.G. Brandon, S. Ranganathan and D.S. Whitmell, Brit. J. Appl. Phys. 15, 55 (1964).

12. The total cross-sectional area of the ion beam is $0.5 \mathrm{~cm}^{2}$; therefore, the area occupied by the FIM specimen only represents $\sim 1 \%$ of ion beam's cross-sectional area.

13. Galileo Electro-Optics Corp., Technical Memorandum 600 (Galileo Park, Sturbridge, MA, 1972); W.E. Baumgartner and W.K. Huber, J. Phys. E: Sci. Instrum. 2, 321 (1976). 
14. The Sylvania No. 160 phosphor $(\mathrm{P}-1)$ is a $\mathrm{Zn}_{2} \mathrm{SiO}_{4}$ :Mn material which has a fluorescent and phosphorescent color in the green; it is a medium persistence phosphor.

15. R. Gomer, Field-Emission and Field-Ionization (Harvard University Press, Cambridge, MA, 1961), pp. 168-9.

16. F. Rosebury, Handbook of Electron Tube and Vacuum Techniques (Addison-Wesley, Reading, MA, 1965), p. 207.

17. For example, see Linear Applications (National Semiconductor Corp., Santa Clara, CA, 1973) p. AN31-1 for a description of the operational amplifiers used in the dosimeter circuit. 


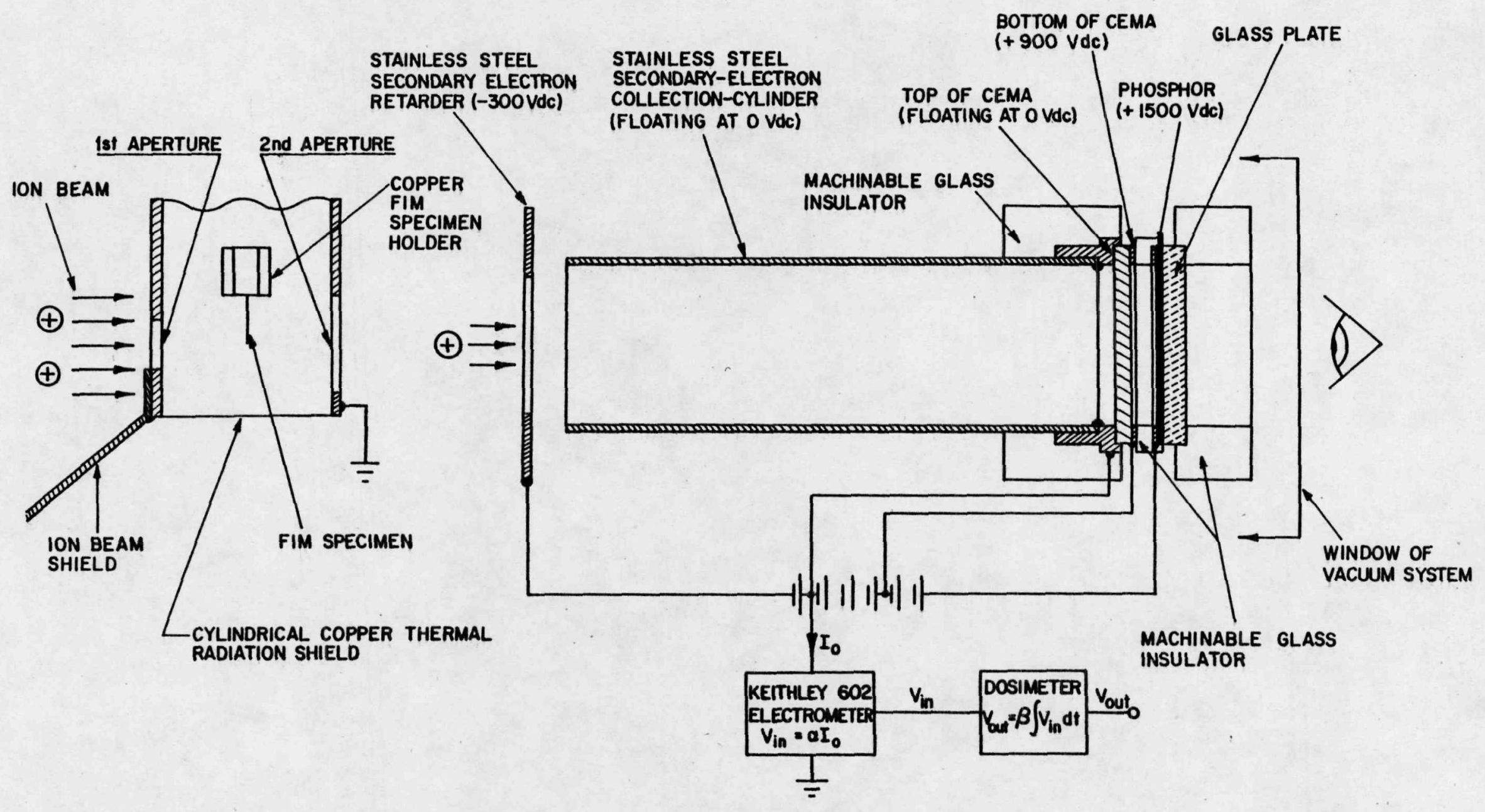




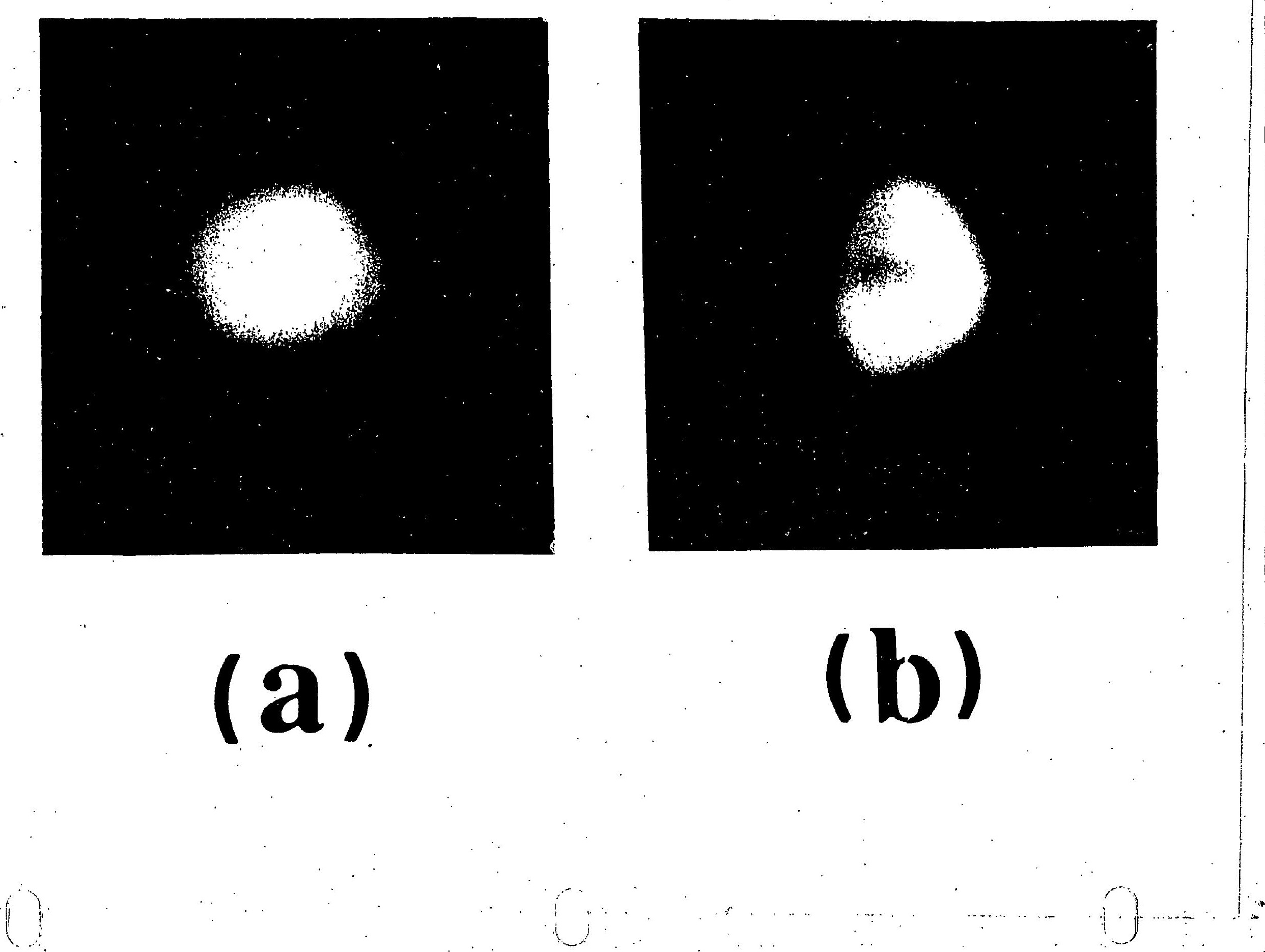


$\longmapsto$ IRRADIATION SYSTEM $\rightarrow+t^{\prime}$ FARADAY CUP $\longrightarrow$

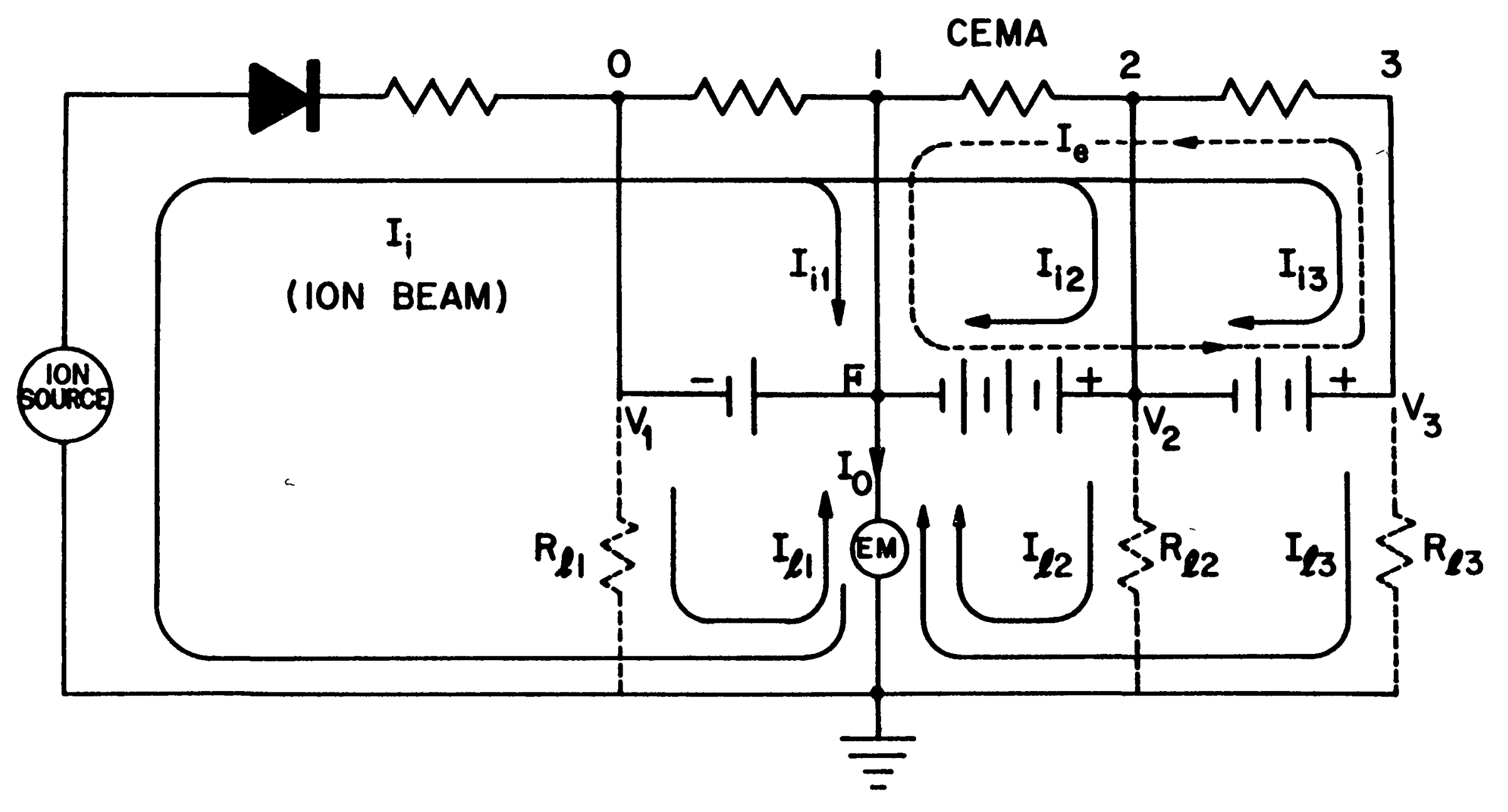




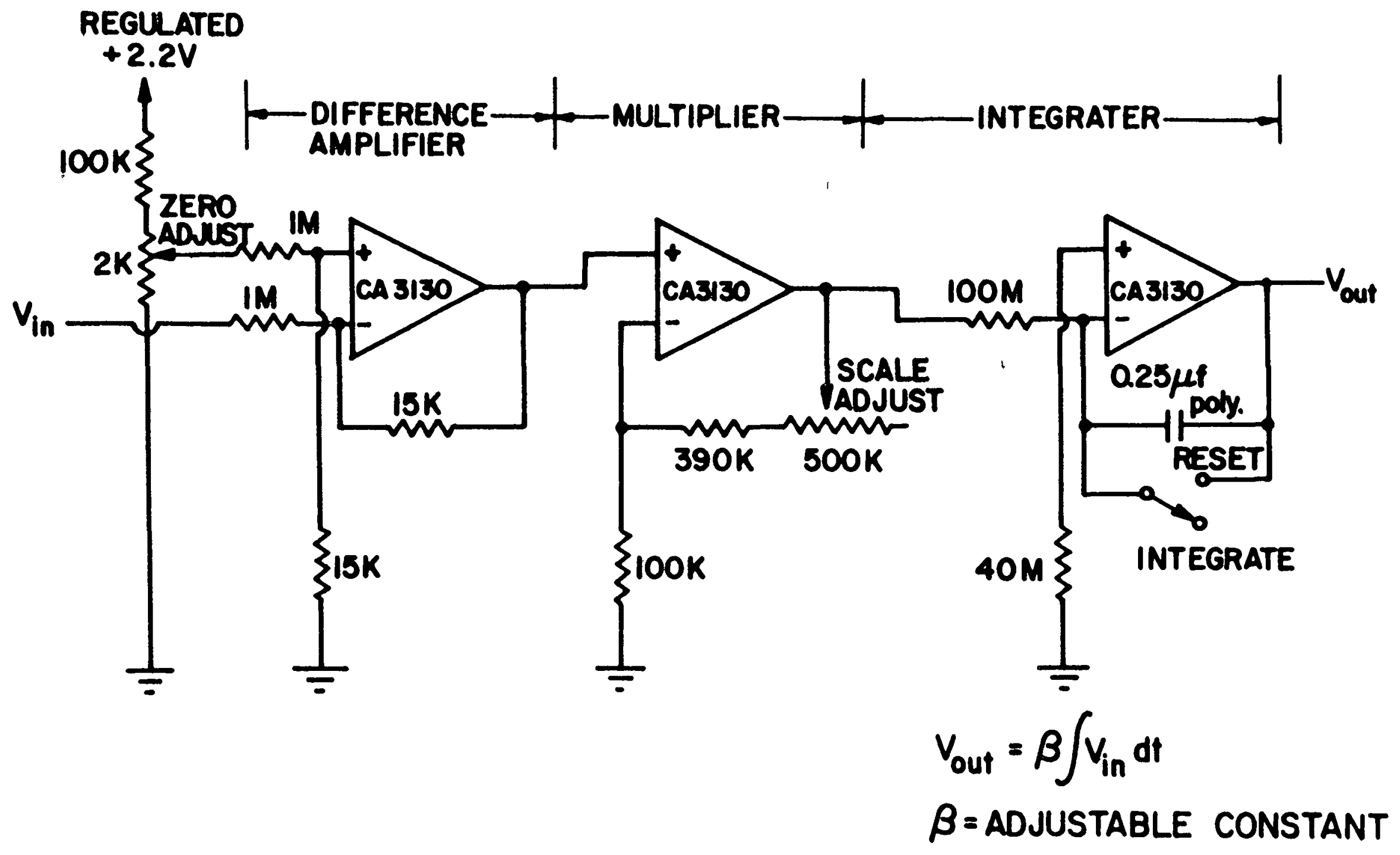

